- Orjinal Makale

\title{
Lenfoproliferatif hastalıklarda splenektomi endikasyonları ve klinik sonuçlarımız
}

\section{Splenectomy indications and clinical results in lymphoproliferative diseases}

\author{
Ramazan SARI $^{* 1} \square$, Mehmet Zeki BULDANLI $^{2} \square$
}

${ }^{1}$ Kartal Dr. Lütfi Kırdar Şehir Hastanesi, Genel Cerrahi Kliniği, İstanbul/TURKEY

${ }^{2}$ Sağlık Bilimleri Üniversitesi, Gülhane Eğitim ve Araştırma Hastanesi, Genel Cerrahi Kliniği, Ankara/TURKEY

\section{Öz}

Amaç: Hematolojik malignitelerde sistemik tutulum nedeniyle cerrahinin faydası oldukça sınırlıdır. Splenektomi özellikle izole dalak lenfomalarında kimi zaman hem tanı hem de tedavi amaçlı gerekir. Bu çalışmanın amacı lenfoma tanısıyla takip edilen hastalarda splenektominin endikasyon ve yararlarını incelemek, operasyon sonrasındaki klinik sonuçlarımızı tartışmaktır.

Gereç ve Yöntemler: Çalışmamıza Ocak 2012 ve Aralık 2019 tarihleri arasında lenfoid malignite nedeniyle hematoloji bölümünce takip edilen ve splenektomi endikasyonuyla tarafımıza yönlendirilen hastalar dahil edildi. Hastalara ait demografik ve klinik veriler ile tedavi sonuçları geriye dönük olarak incelendi.

Bulgular: Çalışmaya toplam 44 hasta dahil edildi. Hastaların splenektomi zamanındaki yaş ortalaması 58,2 ( \pm 12.4$)$ idi. Hastaların \%63,6'sı erkekti. Splenektomi sonrası ortalama takip süresi 12,3 (3-94) aydı. 26 hasta semptomatik splenomegali, 18 hasta medikal tedaviyle düzeltilemeyen trombositopeni ve anemi gibi endikasyonlarla opere edildi. Tedavi sonrası klinik iyileşme splenik marjinal zon lenfomasında diğer lenfoma tiplerine göre daha yüksekti.

Sonuç: Son yıllarda özellikle monoklonal antikorlarla yapılan medikal tedaviler sayesinde lenfoma tedavisinde cerrahi ihtiyacı giderek azalmaktadır. Verilerimiz dalak tutulumu olan lenfoid malignitelerde ve özellikle splenik marjinal zon lenfomasında splenektominin etkili ve güvenli bir tedavi seçeneği olduğunu göstermektedir.

Anahtar Sözcükler: lenfoma; marjinal zon lenfoma; splenektomi

Sorumlu Yazar*: Ramazan SARI, Kartal Dr. Lütfi Kırdar Şehir Hastanesi, Genel Cerrahi Kliniği, İstanbul/TURKEY 


\section{Abstract}

Aim: The benefits of surgery are very limited in hematological malignancies due to systemic involvement. Splenectomy is sometimes required for both diagnosis and treatment, especially in isolated splenic lymphomas. The aim of this study is to examine the indications and benefits of splenectomy in patients with lymphoma diagnosis and to discuss our postoperative clinical results.

Material and Methods: Patients who were followed up by the hematology department for lymphoid malignancy between January 2012 and December 2019 and referred to us with the indication of splenectomy were included in our study. The demographic and clinical data of the patients and the treatment results were analyzed retrospectively.

Results: A total of 44 patients were included in the study. The mean age of the patients at the time of splenectomy was 58.2 ( \pm 12.4). Sixty three percent of the patients were male. The mean follow-up time after splenectomy was 12.3 (394) months. Twenty six patients were operated due to symptomatic splenomegaly, 18 patients were operated due to thrombocytopenia and anemia that could not be corrected by medical therapy. Clinical improvement after treatment was higher in splenic marginal zone lymphoma than in other types of lymphoma.

Conclusion: In recent years, the need for surgery in the treatment of lymphoma has been decreasing, especially through medical treatments with monoclonal antibodies. Our data show that splenectomy is an effective and safe treatment option in lymphoid malignancies and especially in splenic marginal zone lymphoma.

Keywords: lymphoma; marginal zone lymphoma; splenectomy

\section{Giriş}

Dalak hematopoetik ve immünolojik fonksiyonları nedeniyle oldukça önemli bir organdır. Her ne kadar korunması amaçlansa da hematolojik ve lenfoproliferatif hastalıkların tanı veya tedavisinde bazen splenektomi kaçınılmazdır. Elektif splenektominin en temel endikasyonu benign veya malign hematolojik bozukluklardır [1].

Hematolojik hastalıklarda medikal tedaviye yanıtsız olgularda veya başarısızık durumunda sık başvurulan etkili bir tedavi yöntemidir [2]. Lenfoproliferatif hastalıklarda ise medikal tedavi alternatiflerinin artması ve dalağın immün sistemdeki önemli rolü nedeniyle splenektomi uygulamaları azalmaktadır. Ayrıca bu hastalıklarda sistemik tutulum nedeniyle splenektominin faydası da oldukça sınırıdır. Önceleri tanı amaçlı yapılan operasyonlar yerini daha minimal invaziv bir yaklaşım olan görüntüleme eşliğindeki biyopsilere bırakmıştır [3]. Son yıllarda gelişen modern tedavi alternatifleri ve monoklonal antikorlar sayesinde splenektomi gerekliliği daha da azalmıştır. Genellikle masif splenomegaliye bağlı gastrointestinal ya da solunum sistemi ile ilgili klinik belirtiler oluştuğunda veya hipersplenizm nedenli düzeltilmesi mümkün olmayan anemi, trombositopeni varlığında alternatif tedavi olarak başvurulur. Sadece primer dalak lenfomalarında küratif amaçlı splenektominin yeri vardır. Masif splenomegaliyle seyreden diğer lenfoproliferatif bozukluklarda ise debulking prosedürünün bir bileşeni olarak uygulanabilir [4]
Gelişen biyomedikal teknoloji ve minimal invaziv cerrahinin artan önemi ile birlikte laparoskopik splenektomi dalak boyutlarının normal olduğu birçok hastalıkta standart tedavi haline gelmiştir [5]. Masif veya ultra masif dalak varlığında ise Avrupa Endoskopik Cerrahi Derneği (EAES) tarafından el yardımlı laparoskopik splenektomi ya da açık splenektomi önerilmektedir [6]. Altta yatan hastalığa bağlı oluşabilecek morbidite, mortalite ve medikal tedavinin yan etkileri düşünüldüğünde gittikçe karmaşıklaşan tedavi ortamında splenektominin faydaları oldukça fazladır [7]. Fakat splenektominin de invaziv bir girişim olduğu unutulmamalı multidisipliner değerlendirme ile kar/zarar analizi yapılarak cerrahi kararı en doğru şekilde verilmeye çalışılmalıdır.

$\mathrm{Bu}$ çalışmadaki amacımız lenfoma tanısıyla takip edilen hastalardaki splenektomi endikasyonlarını incelemek, operasyon sonrasında düzelen klinik bulguları tartışmaktır.

\section{Gereç ve Yöntemler}

Bu çalışma için Ocak 2012 ile Aralık 2019 tarihleri arasında kliniğimizde splenektomi uygulanan toplam 274 hastaya ait veriler geriye dönük incelendi. Çalışmaya bu hastalar içerisinden sadece lenfoid malignite nedenli hematoloji kliniğince takibi sırasında splenektomi endikasyonuyla polikliniğimize konsülte edilen ve elektif koşullarda opere edilen 44 hasta dahil edildi. Diğer nedenlerle opere edilen ve acil cerrahi uygulanan hastalar çalışma dışı bırakıldı. Çalışma Helsinki bildirgesine uygun olarak yapıldı ve yerel etik kurul 
tarafından onaylandı (Proje no:514/188/8). Veriler doğrudan hastane elektronik veri tabanı ve matbu hasta dosyaları retrospektif olarak taranarak elde edildi.

Hastalara ait demografik verilerin yanı sıra, operasyon öncesi ve sonrasındaki klinik, laboratuvar bulgular, cerrahi öncesi uygulanan medikal tedaviler, splenektomi endikasyonları, operasyon sonrası gelişen komplikasyonlar ve cerrahinin sağladığı fayda analiz edildi. Lenfoma tipini belirlemek için Dünya Sağlık Örgütü (WHO) 2016 sınıflandırılması kullanıldı ve splenik marjinal zon lenfoma (SMZL) tanılı hastalar Grup 1 diğer Hodgkin dışı lenfoma (NHL) tanılı hastalar ise Grup 2 olarak tanımlandı. Hastalara elektif operasyonun 2 hafta öncesinde pnömokok, meningokok ve hemofilus influenza tip B aşıları uygulandı. Tüm hastalar açık cerrahi teknikle opere edildi. Hastalara operasyon sonrası 1 hafta boyunca profilaktik oral antibiyotik ve tromboemboli profilaksisi için düşük molekül ağırlıklı heparin verildi. Takiplerde platelet sayısı 1 milyon üstünde ölçülen hastalara asetil salisik asit başlandı.

İstatistiksel analizler için Statistical Package for Social Scienses (SPSS) 21.0 programı kullanıldı. Sürekli değişkenlerin değerlendirilmesinde normal dağılım gösteren veriler ortalama $\pm S D$, normal dağılım göstermeyenler ortanca (min-max) olarak belirtildi. Kategorik değişkenler frekans (\%) olarak sunuldu.

\section{Bulgular}

Çalışma için belirlenen periyotta splenektomi yapılan 274 hastadan lenfoproliferatif malignite tanısı olan 44 (\%16) hasta çalışmaya dahil edildi. Bu hastaların operasyon zamanındaki yaş ortalaması 58,2 ( $\pm 12,4)$ idi ve hastaların çoğunluğunu $(\% 65,9)$ erkek hastalar oluşturmaktaydı. Tüm hastalar NHL tanılıydı ve baskın histolojik tip $28(\% 63,6)$ hasta ile SMZL idi. Splenektomi endikasyonları incelendiğinde 26 (\%59) hasta semptomatik splenomegali, 18 (\%41) hasta medikal tedaviyle düzeltilemeyen anemi ve trombositopeni nedeniyle opere edildi. Operasyon öncesi dönemde SMZL tanı hastalarda anemi daha sıktı, trombositopeni oranı ise her iki grupta benzerdi. Hastaların \%72'sine ilk tedavi olarak kemoterapi başlanmıştı. Hastalara ait detaylı demografik ve klinik veriler tablo-1'de sunuldu.

Preoperatif değerlendirmede Grup 1'deki hastaların ortalama hemoglobin ve platelet değerleri daha düşüktü. Splenektomi sonrası bu parametrelerin her iki grupta da yükseldiği gözlendi. (Tablo 2) Splenektomi sonrası ortalama takip süremiz 12,3 (3-94) aydı.

İki gruptaki morbidite oranı eşitti. Grup 1'de 7 (\%25) Grup 2'de 4 (\%25) hasta olmak üzere toplam 11 (\%25) hastada çeşitli komplikasyonlar gözlendi. Peroperatif 3 hastanın kanama nedenli transfüzyon ihtiyacı oldu. Postoperatif dönemde ise sadece 1 hastada transfüzyon gerektirecek kadar kanama gözlendi. Operasyon sonrası takiplerde 3 hastada subfrenik apse, 2 hastada atelektazi, 1 hastada derin ven trombozu ve 1 hastada akut pankreatit saptandı. Bir hastada postsplenektomi sepsise bağlı mortalite görüldü ve mortalite oranı $\% 2,2$ olarak saptandı. Operatif komplikasyonlara ait veriler ayrıntılı olarak tablo 3'de gösterildi.

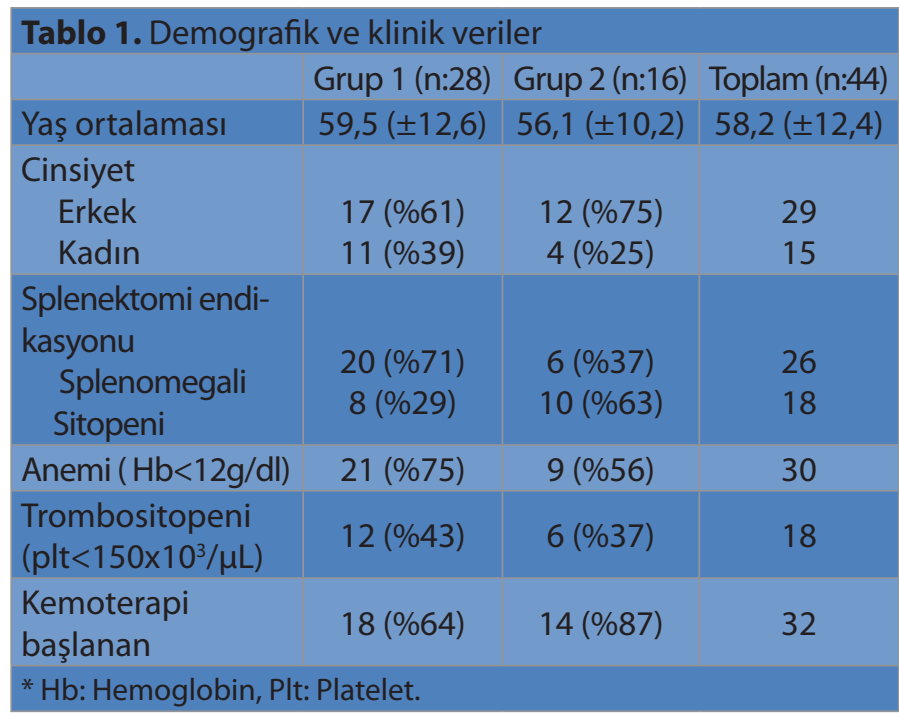

\begin{tabular}{|c|c|c|}
\hline & Grup 1 & Grup 2 \\
\hline $\begin{array}{l}\text { Ortalama Hemoglobin (g/dL) } \\
\text { Preoperatif } \\
\text { Postoperatif }\end{array}$ & $\begin{array}{l}10,4 \pm 2,3 \\
11,5 \pm 2,6\end{array}$ & $\begin{array}{l}11,1 \pm 1,9 \\
11,9 \pm 2,1\end{array}$ \\
\hline $\begin{array}{l}\text { Ortalama Platelet }\left(10^{3} / \mathrm{uL}\right) \\
\text { Preoperatif } \\
\text { Postoperatif }\end{array}$ & $\begin{array}{c}212 \pm 94 \\
470 \pm 251\end{array}$ & $\begin{array}{l}266 \pm 124 \\
493 \pm 283\end{array}$ \\
\hline
\end{tabular}

\begin{tabular}{l|l|l|l|}
$\begin{array}{l}\text { Tablo 3: Postoperatif komplikasyonlar } \\
\text { Grup 1 }\end{array}$ & Grup 2 & Toplam \\
\hline $\begin{array}{l}\text { Kanama } \\
\text { - Peroperatif }\end{array}$ & 2 & 1 & $3(\% 6,8)$ \\
\hline - Postoperatif & 1 & 0 & $1(\% 2,2)$ \\
\hline Subfrenik apse & 2 & 1 & $3(\% 6,8)$ \\
\hline Atelektazi & 1 & 1 & $2(\% 4,5)$ \\
\hline Tromboemboli & 0 & 1 & $1(\% 2,2)$ \\
\hline Akut Pankreatit & 1 & 0 & $1(\% 2,2)$ \\
\hline Sepsise bağlı mortalite & 0 & 1 & $1(\% 2,2)$ \\
\hline
\end{tabular}

\section{Tartışma}

Lenfoma genellikle sistemik tutulum gösteren bir hastalık olduğundan tedavisinde cerrahi uygulama oldukça sınırlıdır. Splenektomi lenfoma tanısı olan hastalarda genellikle splenomegaliye bağlı gelişen klinik semptomları gidermek, sitopeniyi düzeltmek veya tedavide kür sağlamak amacıyla 
uygulanabilir. Dünya Sağık Örgütü (DSÖ) tarafından 2001 yılından beri farklı bir kategoride sınılandırılan splenik marjinal zon lenfoması (SMZL) izole dalak tutulumu ile seyreden nadir görülen bir non-Hodgkin lenfoma türüdür [8]. Hastalı̆ın seyrinde genellikle masif izole splenomegali ve hipersplenizme bağlı ciddi sitopeni görülmekte olup splenomegali ve sitopeni görülme oranı diğer lenfomalara kıyasla daha yüksektir [9]. Bu nedenle tedavisinde ilk basamak yaklaşım splenektomi veya rituksimabla uygulanan immünoterapidir. Rituksimab tedavisinin düşük toksisite ile yüksek yanıt (\%88-95) sağladığı yönünde yayınlar mevcuttur [10,11]. Fakat uygun tedavi rejimi ve ne kadar süre devam edeceği henüz açıklığa kavuşmamışır. Ayrıca literatürde splenektomiyi rituksimab veya kemoterapi ile karşılaştıran bir çalışma bulunmamaktadır. SMZL tanılı hastalarda splenektomi sıklıkla gerekmekte ve cerrahi tedavi kimi zaman ilk seçenek olarak önerilmektedir [12]. Bizim çalışmamızda da literatüre benzer şekilde lenfoma nedenli splenektomi yapılan hastaların \%63,6'sını SMZL tanılı hastalar oluşturmaktadır.

Splenektomi için seçilen hastalar immün süpresyonu ve genel anestezi altında abdominal cerrahiyi tolere edebilecek performansta olmalıdır. Hematolojik hastalıklarda splenektomi sonrası düşük oranlarda morbidite ve mortalite gözlenir. Splenektomi sonrası komplikasyon görülme oranı \% 8-52 arasında değişmekte olup malignite nedenli yapılan ameliyatlarda bu oran yüksektir [13]. Bagradio ve arkadaşlarının hematolojik hastalıklar nedenli splenektomi yapılan 1715 vakayı içeren çalışmasında morbidite $\% 17$ ve mortalite $\% 1,6$ oranında saptanmıştır [14]. Aynı çalışmada splenektomi nedenleri benign ve malign olarak ayrıldığında ise malign hasta grubunda bu oranın \%27,2 olduğu raporlanmıştır. Bizim çalışmamızdaki morbidite ve mortalite oranları sırasıly $\% 25$ ve $\% 2,2$ 'dir.

Kanama ve enfeksiyon en sık görülen komplikasyonlardır. Musallam ve arkadaşlarının yaptığı bir çalışmada splenektomi sonrası transfüzyon oranını \%29,4 (laparoskopi sonrası \%11,2 açık cerrahi sonrası \%47) olarak bulmuştur [15]. Splenektomi sonrası gelişen enfeksiyon tablosunda etkeni tanımlamak oldukça zordur. Bu nedenle elektif operasyondan en az 2 hafta önce kapsüllü bakterilere karşı aşılama önerilmektedir. Yapılan çalışmalar benign ve malign koşullara göre değişmekle birlikte splenektomi sonrası enfeksiyon görülme oranlarını \%1 ile \%6,3 arasında bildirmiştir [14-18]. Çalışmamızda enfektif komplikasyonu olan $3(\% 6,8)$ hastamız vardı ve bu hastalardan 1 'inde $(\% 2,2)$ sepsis nedenli mortalite gözlendi. Trombotik komplikasyonların ( derin ven trombozu, pulmoner emboli vs.) görülme sıklığı 3812 hastayı içeren geniş bir kohort çalışmasında değerlendirildi ve splenektomiden sonraki 90 gün içinde $71(\% 1,9)$ hastada venöz tromboemboli saptandı ve bu oran hem genel popülasyondan $(\% 0,06)$ ve hem de appendektomi sonrası $(\% 0,6)$ görülen oranlardan belirgin yüksekti [19]. Literatürde yer alan diğer çalışmalar da benzer şekilde splenektomiyi takiben venöz tromboemboli görülme oranının \%1,8-\%3,3 arasında değiştiğini bildirmiştir $[14,15,20]$. Çalışmamızda bu oran $\% 2,2$ olarak bulundu.

Postoperatif enfeksiyöz komplikasyonlar; antibiyotik profilaksisi, uygun intraoperatif Isı kontrolü, kateter (nazogastrik, üriner ve santral venöz gibi) ve drenlerin erken çekilmesi gibi birkaç basit önlemle azaltılabilir [21]. Operasyon öncesi ve sonrası erken dönemde tromboemboli profilaksisi özellikle malign hastalarda oldukça kritiktir. Preoperatif anemi, koagülopati ve kanama riski yüksek operasyon nedeniyle transfüzyon ihtiyacının arttığı aşikardır.Splenektomi de dahil olmaküzere cerrahi uygulamalarda 1 ünite kan transfüzyonun artmış enfeksiyöz komplikasyon ve mortalite oranlarıyla ilişkili olduğu saptanmıştır [22].

Çalışmamızın retrospektif olması ve literatüre kıyasla nispeten az sayıda hasta içermesi başlıca kısıtlılıklarıdır.

\section{Sonuç}

Medikal tedaviler ve özellikle de monoklonal antikorlardaki gelişmeler hematolojik hastalıklarda splenektomi endikasyonlarını oldukça azaltmıştır. Yine de lenfoid malignitelerde splenomegaliye bağlı klinik semptomlar ve tedaviye bağı sitopeni varlığında splenektomi düşük morbidite ve mortalite oranlarıla güvenle uygulanabilmesi nedeniyle tedavi alternatifi olarak önemini korumaktadır.

\section{Çıkar çatışması / finansal destek beyanı}

Bu yazıdaki yazarların herhangi bir çıkar çatışması yoktur. Yazının herhangi bir finansal desteği yoktur.

\section{Kaynaklar}

1. Bonnet S, Guedon A, Ribeil J-A, Suarez F, Tamburini J, Gaujoux S. Indications and outcome of splenectomy in hematologic disease. Journal of visceral surgery 2017; 154: 421-9

2. Ciftciler R, Pasayeva A, Aksu S bet al. Indications and Outcomes of Splenectomy for Hematological Disorders. Open Med (Wars) 2019; 14: 491-6.

3. Tokue H, Hirasawa S, Morita H et al. Percutaneous image-guided biopsy for non-mass-forming isolated splenomegaly and suspected malignant lymphoma. PLoS One 2014; 9: 111657. 
4. Onisâi $M$, Vlădăreanu $A M, N i c a ~ A$ et al. Splenectomy in Lymphoproliferative Disorders: A Single Eastern European Center Experience. Medicina (Kaunas) 2019; 56: 12.

5. Uranüs S, Dorr K. Laparoscopy in Abdominal Trauma. Eur J Trauma Emerg Surg 2010; 36: 19-24.

6. Habermalz B, Sauerland S, Decker G et al. Laparoscopic splenectomy: the clinical practice guidelines of the European Association for Endoscopic Surgery (EAES). Surg Endosc 2008; 22: 821-48.

7. Alobuia WM, Perrone K, Iberri DJ, Brar RS, Spain DA, Forrester JD. Splenectomy for benign and malignant hematologic pathology: Modern morbidity, mortality, and long-term outcomes. Surg Open Sci 2020; 2: 19-24.

8. Swerdlow SH, Campo E, Harris NL, et al, eds. WHO Classification of Tumors of the Haematopoietic and Lymphoid Tissues. IARC Press; 2017.

9. Rodgers, G. Thrombocytopenia: Pathophysiology and classification. In Wintrobe's Clinical Haematology, 12th ed.; Greer, J., Foerster, J., Lukens, J., Rodgers, G., Paraskevas, F., Glader, B., Eds.; Lippincott Williams \& Wilkins: Philadelphia, PA, USA, 2009; pp. 1289-91.

10. Kalpadakis, C, Pangalis GA, Vassilakopoulos, TP, Sachanas $S$, Angelopoulou MK. Treatment of splenic marginal zone lymphoma: should splenectomy be abandoned? Leukemia \& Lymphoma 2013; 55: 1463-70.

11. Bennett M, Schechter GP. Treatment of splenic marginal zone lymphoma: splenectomy versus rituximab. Semin Hematol 2010; 47: 143-7.

12. Lenglet J, Traullé $\mathrm{C}$, Mounier $\mathrm{N}$ et al. Long-term follow-up analysis of 100 patients with splenic marginal zone lymphoma treated with splenectomy as first-line treatment. Leuk Lymphoma 2014; 55: $1854-60$.

13. Cadiere B, Grilli A, Bron D. Comparison of Laparoscopic Splenectomy Outcomes for Benign and Malignant Hemopathies. J Laparoendosc Adv Surg Tech A 2020; 30: 1172-6.
14. Bagrodia N, Button AM, Spanheimer PM, Belding-Schmitt ME, Rosenstein LJ, Mezhir JJ. Morbidity and Mortality Following Elective Splenectomy for Benign and Malignant Hematologic Conditions: Analysis of the American College of Surgeons National Surgical Quality Improvement Program Data. JAMA Surg 2014; 149: 1022-9.

15. Musallam KM, Khalife M, Sfeir PM et al. Postoperative outcomes after laparoscopic splenectomy compared with open splenectomy. Ann Surg 2013; 257: 1116-23.

16. Winslow ER, Brunt LM. Perioperative outcomes of laparoscopic versus open splenectomy: a meta-analysis with an emphasis on complications. Surgery 2003; 134: 647-53.

17. Rosen M, Brody F, Walsh RM, Tarnoff M, Malm J, Ponsky J. Outcome of laparoscopic splenectomy based on hematologic indication. Surg Endosc 2002; 16: 272-9.

18. Balague C, Targarona EM, Cerdan G, et al. Long-term outcome after laparoscopic splenectomy related to hematological diagnosis. Surg Endosc 2004; 18: 1283-7.

19. Thomsen RW, Schoonen WM, Farkas DK, Riis A, Fryzek JP, Sørensen $\mathrm{HT}$. Risk of venous thromboembolism in splenectomized patients compared with the general population and appendectomized patients: a 10-year nationwide cohort study. J Thromb Haemost 2010; 8: 1413-6.

20. Taner T, Nagorney DM, Tefferi A et al. Splenectomy for massive splenomegaly: long-term results and risks for mortality. Ann Surg 2013; 258: 1034-9.

21. Berenguer CM, Ochsner MG Jr, Lord SA, Senkowski CK. Improving surgical site infections: using National Surgical Quality Improvement Program data to institute Surgical Care Improvement Project protocols in improving surgical outcomes. J Am Coll Surg 2010; 210: 737-41.

22. Bernard AC, Davenport DL, Chang PK, Vaughan TB, Zwischenberger JB. Intraoperative transfusion of $1 \mathrm{U}$ to $2 \mathrm{U}$ packed red blood cells is associated with increased 30-day mortality, surgical-site infection, pneumonia, and sepsis in general surgery patients. J Am Coll Surg 2009; 208: 931-7. 